\title{
Numerical Modeling of Bond Formation in Polymer Surface Metallization Using Cold Spray
}

\author{
Asghar Heydari Astaraee ${ }^{1}$ Chiara Colombo ${ }^{1}$ - Sara Bagherifard ${ }^{1}$
}

Submitted: 23 February 2021 / in revised form: 2 May 2021 / Accepted: 29 May 2021 / Published online: 19 July 2021

(C) The Author(s) 2021

\begin{abstract}
Surface metallization of polymeric materials using cold spray technology has gained increasing attention in the past decade. Experimental studies have evidenced multiple challenges of this process regarding continuity and homogeneity of the metallic deposits on polymer substrates. Modeling and simulation tools could be very helpful to assess the efficiency of different strategies suggested for improved deposition at a considerably reduced cost; nevertheless, the efforts to use numerical modeling in this sector have been less successful. Here, we develop a detailed finite element model for the cold spray deposition of metal particles on polymeric substrates to shed light on the underlying deposition mechanisms. The simulation results are compared with the literature experiments to establish the effectiveness of the proposed model. The developed model is able to capture the key phenomena involved in the deposition mechanism particularly the particle and substrate mechanical interlocking and substrate local melting. It is shown that a particle velocity threshold value should be exceeded to achieve an effective mechanical interlocking. The substate thermal domain and melting as well as the effects of particle velocity and size on deformation and particle anchorage are discussed.
\end{abstract}

Keywords cold spray $\cdot$ finite element $\cdot$ modeling $\cdot$ polymer metallization $\cdot$ simulation

Supplementary Information The online version contains supplementary material available at https://doi.org/10.1007/s11666021-01224-9.

Sara Bagherifard sara.bagherifard@polimi.it

1 Department of Mechanical Engineering, Politecnico di Milano, Milan, Italy

\section{List of Symbols}

$\begin{array}{ll}\text { Abbreviations } \\ \text { AH } & \text { Adiabatic heating } \\ \text { ASI } & \text { Adiabatic shear instability } \\ \text { BC } & \text { Boundary condition } \\ \text { CEL } & \text { Coupled Eulerian-Lagrangian } \\ \text { CS } & \text { Cold spray } \\ \text { CTD } & \text { Coupled temperature-displacement } \\ \text { FE } & \text { Finite element } \\ \text { PEEK } & \text { Polyether ether ketone }\end{array}$

\section{Symbols}

$\begin{array}{ll}A & \text { Elastic limit } \\ B & \text { Hardening constant } \\ C & \text { Strain rate constant } \\ m & \text { Thermal exponent } \\ n & \text { Hardening exponent } \\ T & \text { Temperature } \\ T_{0} & \text { Reference temperature } \\ T_{m} & \text { Melting temperature } \\ \varepsilon_{p} & \text { True plastic strain } \\ \dot{\varepsilon} & \text { Plastic strain rate } \\ \dot{\varepsilon}_{0} & \text { Plastic strain rate } \\ \sigma & \text { True stress } \\ 3 \mathrm{D} & \text { Three dimensional } \\ D_{p} & \text { Particle's diameter } \\ R_{p} & \text { Particle's radius } \\ T_{p} & \text { Particle's temperature } \\ V_{p} & \text { Particle's velocity } \\ V_{c r} & \text { Critical velocity of particle for adhesion } \\ V_{\text {int }} & \text { Critical velocity of the particle to be interlocked } \\ & \text { mechanically }\end{array}$




\section{Introduction}

Cold gas dynamic spray or briefly cold spray (CS) is a pioneering deposition technique that is primarily used to produce relatively thick coatings of fine powder $(1-50 \mu \mathrm{m})$ sprayed on the surface of materials. Solid particles are accelerated to supersonic velocities $(300-1200 \mathrm{~m} / \mathrm{s})$ by the expansion of a pressurized and heated gas (normally nitrogen or helium) in a convergingdiverging nozzle (Ref 1). The term "cold" refers to the relatively low processing temperatures and the solid-state nature of the process, especially when compared to other thermal spray processes such as flame spray, electric arc wire spray and plasma spray. This feature of CS discloses interesting capabilities for materials sensitive to high temperatures. In optimal conditions, the high-velocity particles exiting from the nozzle impact the target surface and bond to the substrate or the already deposited particles as a result of adiabatic shear instability (ASI), which occurs at the interface (Ref 2). CS is recognized as a versatile process since, in addition to surface coatings, its use has been expanded to structural repair applications and additive manufacturing owing to high deposition rates, the possibility of working at large scales and adequate mechanical strength of its deposits (Ref 3,4).

The ever-advancing material processing techniques have recently discovered outstanding capabilities of CS technology in improving the functionality of products made of plastics and polymer matrix composites by the deposition of metallic surface coatings. As the name suggests, surface metallization of polymers can expand their use or enhance their performance by improving thermal and electrical properties (Ref 5), wear and erosion resistance (Ref 6), electromagnetic shielding (Ref 7) and lightning strike protection (Ref 8). Frequently known as surface metallization, different methods such as plating (Ref 9), physical and chemical vapor deposition (Ref 10, 11), thermal spray (Ref 12) and CS (Ref 13) have been used for producing metallic coatings on plastics. Metallization using CS unpacks several advantages compared to its counterparts regarding processing costs, coating thickness, metal oxidation, thermal degradation of the substrate and size limitations.

In the last two decades, the metallization of polymeric materials using CS technology has been growingly investigated by several research groups and interesting developments have been reported. However, the progress is still in its initial steps and further effort must be spent in this field to bypass the obstacles in the efficient deposition of coatings with favorable properties. A recent review by Astarita et al. (Ref 14) on CS deposition of metallic coatings on the polymeric substrates provides an immediate state of the art. Understanding the overriding bonding mechanisms and developing novel techniques to enable the CS deposition on fiber-reinforced composites are examples of the main challenges.

Contrary to the case of strong bonding formation in CS between metallic materials where ASI is known to play a key role (Ref 15), for polymers ASI has no effective part in the bond formation of the first deposited layer, as the substrate chemical nature is different from the metallic particle. Therefore, the main bonding mechanism is believed to be mechanical interlocking (Ref 16). In other words, the harder particle is embedded or anchored in the softer polymer.

The numerical study of particle deformation and bonding phenomenon during deposition can bring significant insight at reduced cost considering the challenges of experimental investigation of such small size and time scales. Also, process optimization complexities due to the numerous material and processing parameters could be overcome, to some extent, by simulation tools to reduce the experimental effort. Several modeling techniques have been successfully developed to model CS for the impact of metallic particles on metallic substrates based on the finite element (FE) method (Ref 17, 18). In the case of metal deposition on polymer substrates, however, there are fewer numerical studies available and the reported results are often showing discrepancies with experiments highlighting the complexity in modeling the bonding between impacting metal particles to the polymer substrates. Małachowska (Ref 19) conducted an FE analysis of particle impact to study the bonding mechanism of copper and tin particles on Polyamide 6. The model was built in the Lagrangian space with a coupled thermal-structural analysis. Johnson-Cook model was considered for the particle material, whereas an elastic-viscoelastic-viscoplastic model primarily developed for semi-crystalline polymers was implemented for the substrate. The model resulted in surprisingly high stresses and temperatures, especially near the interface. Besides, after the particle rebound, the substrate deformation was fully recovered due to its hyperelastic behavior, which did not reflect the real situation of particle bonding. Bortolussi (Ref 20) modeled copper particle impact on PEEK using a 2D axisymmetric model with a rigid non-deformable spherical particle. The penetration depth of individual particles into the PEEK substrate was compared with the experimental data. The author concluded that the numerical results overestimated the penetration depths; in addition, no evidence for the interlocking was observed. Chen et al. (Ref 21) developed a 2D axisymmetric Lagrangian FE model to investigate the impact process and the deformation behavior of a spherical copper particle on a PEEK substrate. In experiments, wrinkling and jetting phenomena were observed on the polymer around the deposited single 
particles. This effect was more pronounced with an increase in the gas pressure. The simulations indicated the formation of a jet due to the severe plastic deformation of the substrate. Although the observed jet in the simulations did not cover the particle and did not show a real particle embedment as it happened in the experiments, it was concluded that the high-temperature jet softened and formed the mechanical interlocking. Overall, reviewing the available numerical models indicates multiple challenges in capturing the real phenomenon occurring during particle bonding on polymeric substrates. Mechanical interlocking is to be a direct outcome of the FE analysis. In other words, the models should be able to show the metal/polymer interface interactions based on the viscoplastic flow of the polymeric substrate (Ref 22). This contrasts with the modeling of the metallurgical bonding, which is not straightforward unless the bonding criteria are introduced into the model. However, till now, no numerical approach has been able to offer a clear description of mechanical interlocking as the key mechanism responsible for the metal particle to polymer substrate bonding and the effect of main processing parameters on its extent.

Here, we focus on the deposition behavior of particles on the polymeric substrate as the key factor for a successful coating since it provides the base layer for the coating's growth and establishes the adhesion strength. A detailed numerical model is developed to study the deformation behavior of a single-particle impact deposition. A system of a copper particle and a polyether ether ketone (PEEK) substrate is selected since it has attained substantial consideration in the literature with enriched experimental results, well suited for comparing with the numerical simulations. The numerical model was based on the coupled Eulerian-Lagrangian (CEL) frame, which has shown a great potential for the simulations of CS in solid mechanics and has not been utilized in the numerical modeling of polymer metallization by CS so far. Through the established model, the deformation features induced by CS were examined in detail and were discussed in comparison to the experimental observations from several literature studies. Finally, the effects of particle velocity and size on mechanical interlocking, and substrate melting were analyzed. The developed model sheds light on the deposition mechanisms of metal powders sprayed on polymeric substrates and the apparent bonding mechanisms responsible for the coating's implementation.

\section{Modeling}

The FE software Abaqus/Explicit 2019 was used to buildup the models and run the simulations. CEL model was considered to bypass severe element distortion issues in the soft polymeric substrate that arises in pure Lagrangian analysis and to enable tracing the interface between the particle and the substrate which is challenging in a pure Eulerian analysis (Ref 23). Thus, the particle was modeled as a deformable Lagrangian section and the substrate as an Eulerian section. A three-dimensional (3D) model (see Fig. 1) was built up since Abaqus/Explicit does not allow Eulerian elements in 2D models. The substrate was considered as a cylinder, and the particle was modeled as a sphere offering the possibility to exploit the symmetry of the problem and model only a quarter of the domain, reducing the computational cost. The length and height of the substrate were kept equal to ten times the particle's radius to avoid the influence of boundaries on the stressstrain fields generated upon impact. Particle size was selected to be $20 \mu \mathrm{m}$ unless specified in the text.

The effect of the thermal domain was considered by adopting two different procedures, namely adiabatic heating $(\mathrm{AH})$ and coupled temperature-displacement (CTD). In the $\mathrm{AH}$ analysis, it was possible to apply the nonreflecting outflow boundary condition (BC) to the bottom and side faces of the substrate. This type of $\mathrm{BC}$ is suggested for problems in which the region of interest is small in size compared to the surrounding medium and acts very similarly to infinite elements by minimizing the reflection of dilatational and shear wave energy back into the FE mesh (Ref 24). In the CTD analysis, nonreflecting outflow BC is no more applicable. So, the displacement of the bottom and the outer side faces of the substrate were restrained. The $\mathrm{AH}$ analysis is expected to offer a better view of the mechanical interlocking due to the absence of residual vibrations in the substrate, while the CTD analysis provides the possibility to investigate the thermal domain of the substrate more properly. Symmetric BC was applied to the symmetry faces of the substrate and the particle, in both cases.

Friction and plasticity-induced heating were integrated into the model. The tangential behavior was defined by a friction coefficient assuming a general contact procedure. A friction coefficient value of 0.35 was assigned to the whole model including the interface between the copper particle and PEEK substrate (Ref 25, 26). The particle impact direction was considered normal to the substrate. The velocity of the particle and the temperatures of the substrate and particle were imposed as initial conditions. The initial substrate temperature was set to $25^{\circ} \mathrm{C}$. In the $\mathrm{AH}$ analysis, the particle and substrate were meshed using 8-node C3D8R and EC3D8R elements with reduced integration and hourglass control, respectively. In the CTD analysis, temperature degree of freedom was added to the elements, and thus, C3D8RT and EC3D8RT elements were used for the particle and substrate, respectively. Element size in the deformation zone was refined to $1 / 50$ th 
Fig. 1 Model geometry and mesh details $\left(R_{\mathrm{p}}\right.$ : particle radius)

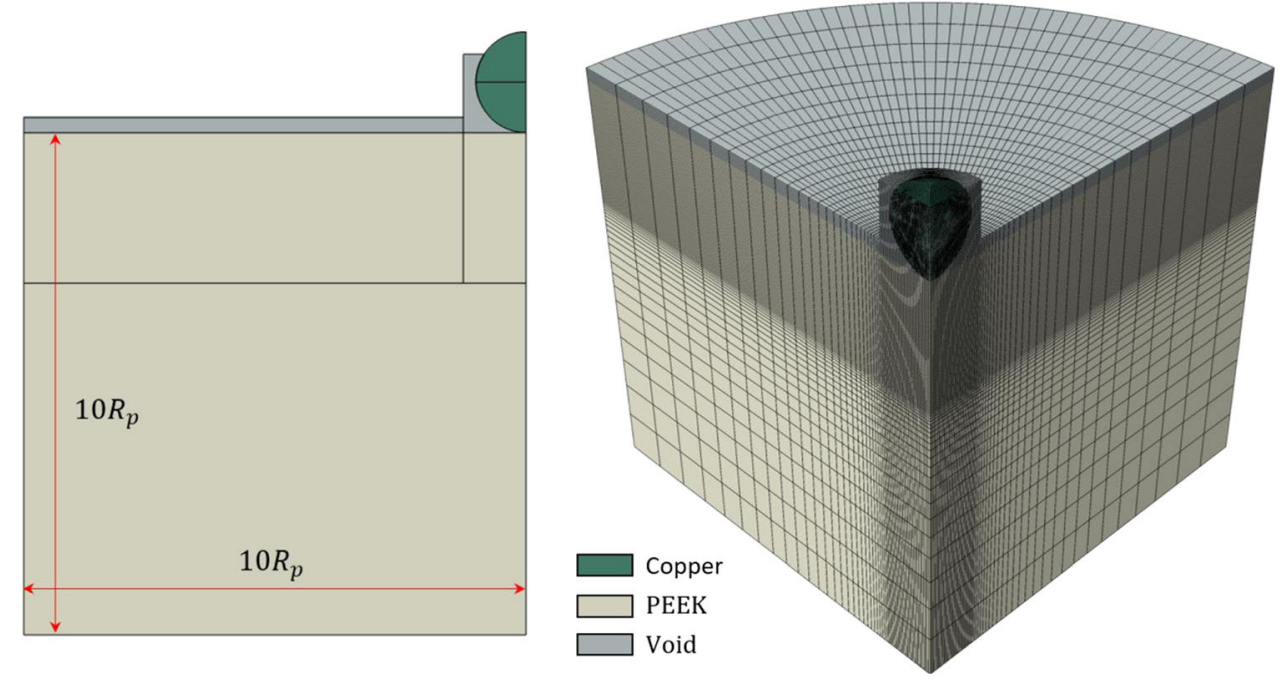

particle's diameter to minimize mesh dependency of the results while maintaining an affordable computational cost.

A Johnson-Cook plasticity model (Ref 27) defined in Eq 1 was utilized for both the particle and substrate materials to replicate the effects of large strains, ultra-high strain rates and thermal softening encountered in CS:

$\sigma=\left[A+B \varepsilon_{p}^{n}\right]\left[1+C \ln \left(\frac{\dot{\varepsilon}}{\dot{\varepsilon}_{0}}\right)\right]\left[1-\frac{T-T_{0}}{T_{\mathrm{m}}-T_{0}}\right]$

where $\sigma, \varepsilon_{\mathrm{p}}, \dot{\varepsilon}$ and $T$ are true stress, true plastic strain, plastic strain rate and temperature variables, respectively. $A, B, n, C, \dot{\varepsilon}_{0}, T_{0}$ and $T_{\mathrm{m}}$ are material constants. Material properties of the copper particle and the PEEK substrate used in the CEL model are provided in Table 1 (Ref 28, 29). For PEEK, the model constants $C$ and $m$ were recalibrated for the strain rates higher than $100 \mathrm{~s}^{-1}$ using the available data in the literature (Ref 30,31$)$ to capture a more genuine plasticity behavior at extremely high strain rates induced by CS (Fig. S1). A VUHARD subroutine was used to implement the new bilinear Johnson-Cook plasticity model. Although the Johnson-Cook model was not fully able to capture the viscoplasticity of PEEK, especially at high temperatures, it was the only available immediate approximation regarding the complexities of characterizing the viscoplastic behavior of PEEK at extremely high strain rates and temperatures encountered in CS. The specific heat capacity of the PEEK increases to several times its value at room temperature, and thus, this parameter was considered to be a function of temperature adapted from (Ref 32). Young's modulus of PEEK increases vs. plastic strain and strain rate, while it decreases vs. temperature (Ref 30, 33). However, for the sake of simplicity, a single value was used in these analyses.
Table 1 Material properties of the copper particle and PEEK substrate

\begin{tabular}{lll}
\hline Property & Copper & \multicolumn{1}{c}{ PEEK } \\
\hline Density, $\mathrm{kg} / \mathrm{m}^{3}$ & 8960 & 1300 \\
Young's modulus, $\mathrm{GPa}$ & 124 & 3.5 \\
Poisson's ratio & 0.34 & 0.40 \\
Thermal conductivity, $\mathrm{W} / \mathrm{m}{ }^{\circ} \mathrm{C}$ & 386 & 0.25 \\
Specific heat, $\mathrm{J} / \mathrm{kg}{ }^{\circ} \mathrm{C}$ & 383 & Variable, see text. \\
Elastic limit, $A, \mathrm{MPa}$ & 90 & 132 \\
Hardening constant, $B, \mathrm{Mpa}$ & 292 & 10 \\
Hardening exponent, $n$ & 0.31 & 1.2 \\
Strain rate constant, $C$ & 0.025 & $0.029\left(\dot{\varepsilon}<100 \mathrm{~s}^{-1}\right)$ \\
& & $0.0834\left(\dot{\varepsilon} \geq 100 \mathrm{~s}^{-1}\right)$ \\
Reference strain rate, $\dot{\varepsilon}_{0}, \mathrm{~s}^{-1}$ & 1.0 & $0.001\left(\dot{\varepsilon}<100 \mathrm{~s}^{-1}\right)$ \\
& & $1.0\left(\dot{\varepsilon} \geq 100 \mathrm{~s}^{-1}\right)$ \\
Thermal exponent, $m$ & 1.09 & 0.634 \\
Melting temperature, $T_{\mathrm{m}},{ }^{\circ} \mathrm{C}$ & 1083 & 341 \\
Reference temperature, $T_{0},{ }^{\circ} \mathrm{C}$ & 25 & 23 \\
Inelastic heat fraction & 0.9 & 0.9 \\
\hline
\end{tabular}

\section{Results and Discussion}

\section{Evaluating the Main Deformation Indexes}

As a first step, the results from an initial benchmark for the selection and verification of the analysis types are given in this section. The focus is on the local deformation, strain and temperature fields, which are the most interesting indexes here.

Figure 2 depicts the deformation contours during the impact of a $20 \mu \mathrm{m}$ copper particle on the PEEK substrate at a particle's velocity $\left(V_{\mathrm{p}}\right)$ of $400 \mathrm{~m} / \mathrm{s}$ and a particle's 
$50 \mathrm{~ns}$

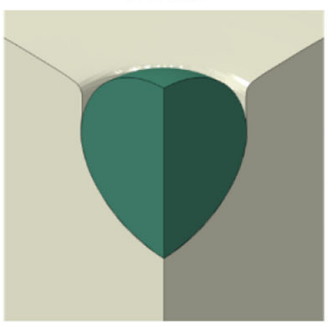

(a)

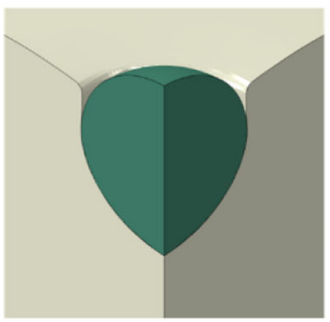

(b)
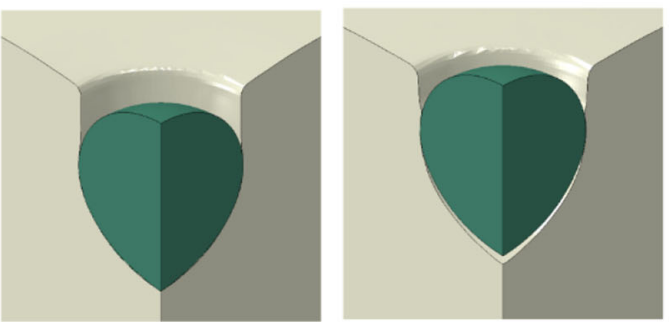

200 ns
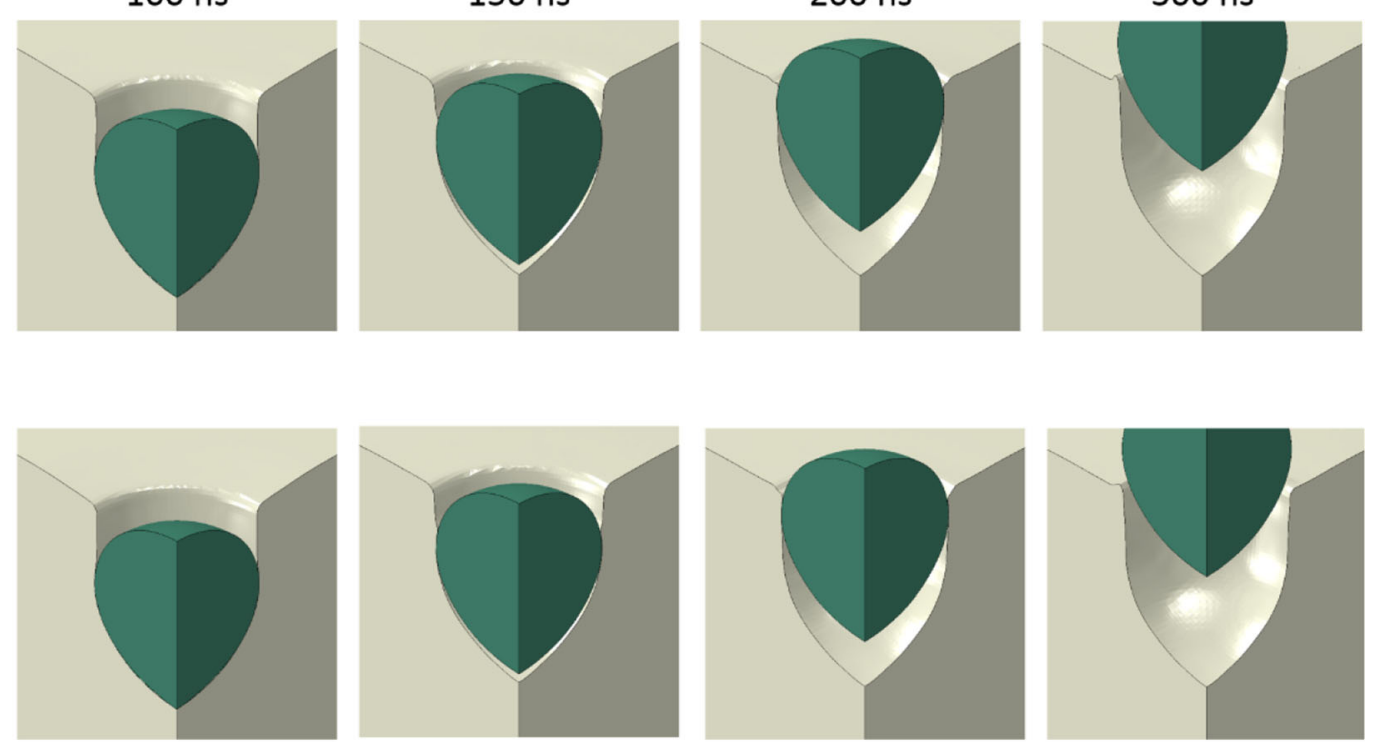

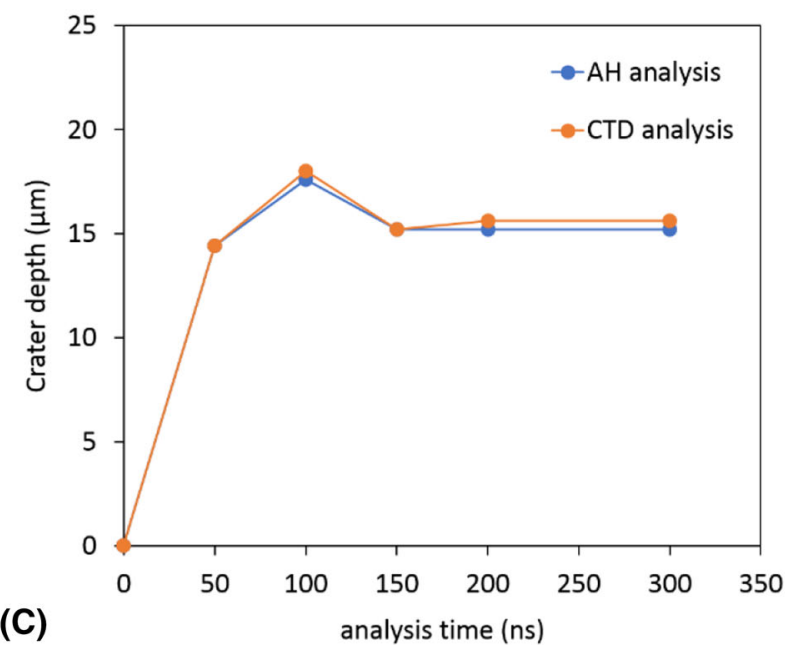

Fig. 2 Deformation contours of the substrate during the impact of the particle with $T_{\mathrm{p}}=150{ }^{\circ} \mathrm{C}$ and $V_{\mathrm{p}}=400 \mathrm{~m} / \mathrm{s}$ : (a) adiabatic heating analysis (b) coupled temperature-displacement analysis (c) crater depth as a function of deposition time.

temperature $\left(T_{\mathrm{p}}\right)$ of $150{ }^{\circ} \mathrm{C}$ at different time intervals obtained from the AH (Fig. 2a) and CTD (Fig. 2b) analyses. Regardless of the analysis type, the analyses show that the particle penetrates the substrate and leaves a crater after rebounding. As regards the deformation behavior of the substrate and the particle including the crater shape and depth, and particle deformation, both approaches lead to almost identical data. Figure 2(c) depicts the crater depth, defined as the distance between the lowest point in the center of the crater and the base undeformed surface. There is a negligible distinction between the two analyses. For both cases, it is observed that at $50 \mathrm{~ns}$, the particle is in the course of penetration and at around $100 \mathrm{~ns}$, the particle reaches its maximum penetration. At $150 \mathrm{~ns}$ and later at $200 \mathrm{~ns}$, the particle is in the phase of a rebound and at
$300 \mathrm{~ns}$, and it has fully detached from the substrate. The maximum penetration point delineates the transition from particle penetration to particle rebound. Generally in CS the impacting particle rebounds due to its momentum in case there is no chemical, metallurgical or sufficient mechanical bonding formed during the impact. The findings in the literature show that the dominant bonding mechanism in CS of metallic particles onto polymers is mechanical interlocking (Ref 16). Based on this, it was assumed that chemical bonding did not play a role and thus was not included in the modeling.

Figure 3(a) and (b) shows the contours of the plastic strain and temperature after particle rebound for the $\mathrm{AH}$ and the CTD analyses developed with the same processing parameters. Since the Eulerian domain is used for the 
Fig. 3 Contours of volumeaveraged equivalent plastic strain and mass-averaged temperature of the substrate in ${ }^{\circ} \mathrm{C}$ after a complete rebound of the particle with $T_{\mathrm{p}}=150{ }^{\circ} \mathrm{C}$ and $V_{\mathrm{p}}=400 \mathrm{~m} / \mathrm{s}$ : (a) adiabatic analysis (b) coupled temperature-displacement analysis
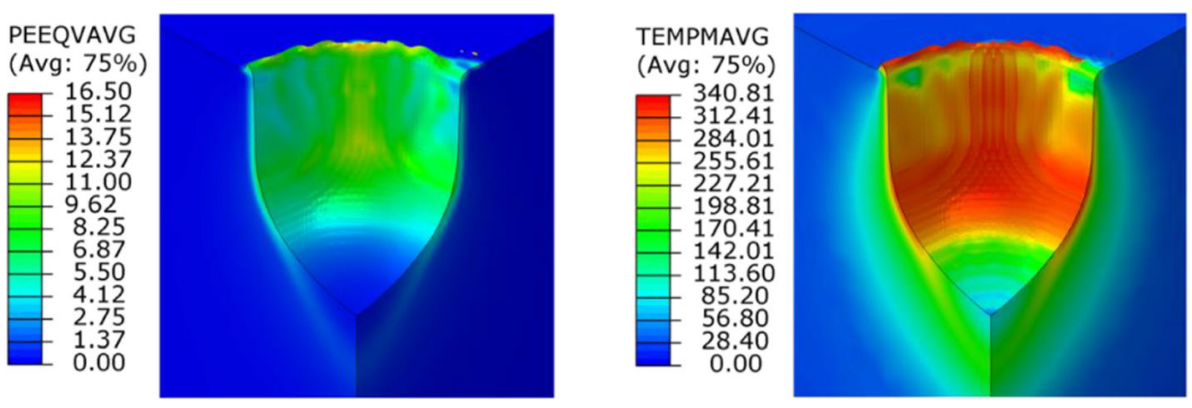

(a)
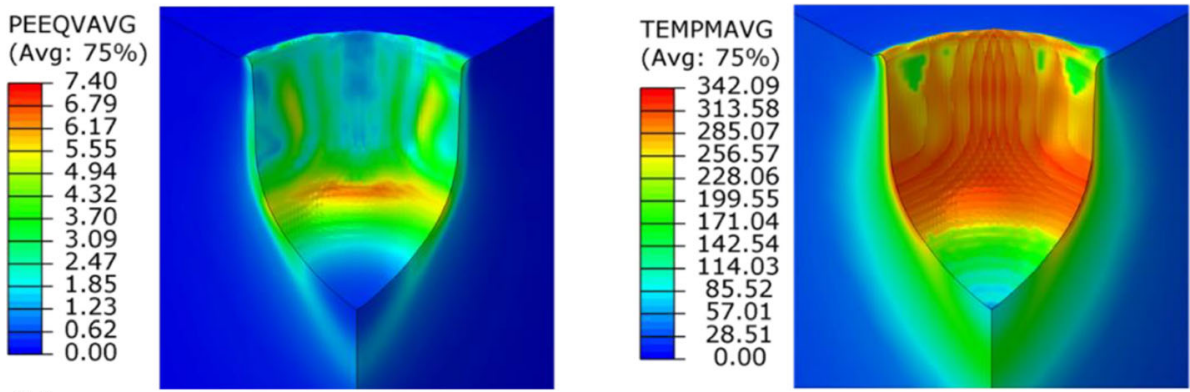

(b)

substrate, the volume-averaged plastic strain and massaveraged temperature variables are provided as outputs from the simulations. It is noted that no material erosion model was used in the current simulations and the volume of the crater was compensated by the elastic deformation of the surrounding large body as well as the semi-infinite BCs on the substrate outer faces. Contrary to deformation, the magnitude and distribution of the plastic strain and temperature are quite different in the two analyses although the discrepancy for the temperature distribution is less notable. Significantly higher plastic strain in the $\mathrm{AH}$ analysis might be correlated with the nature of the process; i.e., the adiabaticity or the limitation in the heat transfer leads to more plastic deformability of the substrate with the resultant higher magnitudes of plastic strain. For further clarification, the thermal cycle in the substrate is studied at three different time steps, as shown in Fig. 4. It is noted that in the $\mathrm{AH}$ analysis, the maximum temperature induced in the substrate is limited to the melting point $\left(341^{\circ} \mathrm{C}\right)$ set in the Johnson-Cook constitutive law. Therefore, after $50 \mathrm{~ns}$ (Fig. 4a), the maximum temperature in $\mathrm{AH}$ analysis already reached the melting point of the PEEK. As regards the same time step in CTD analysis (Fig. 4b), the maximum temperature exceeds the PEEK melting point. The examinations at different time intervals revealed that the region with a temperature higher than the melting point of PEEK is very limited in size with respect to the crater size. Temperatures higher than the melting point are marked as light gray in the color contour spectrum (Fig. 4b). Another observation that can be drawn from the comparison between Fig. 4(a) and (b) is that irrespective of the melted regions, the temperature distribution below the melting point is quite similar in the two analyses.

Comparison of the simulations revealed no noticeable divergence between the two analysis types regarding deformation and crater features. Since this study is mainly focused on the deformation behavior, the authors believe that the $\mathrm{AH}$ analysis with the incorporation of damping $\mathrm{BC}$ would be more successful in the description of the mechanical interlocks. Besides, due to the absence of temperature degree of freedom, the computational cost is reduced in AH analysis. Thus, the next set of simulations for investigating the deformation features and interlocking phenomena was mainly done based on the AH analysis. However, as the CTD analysis seemed to provide a more realistic temperature field also in terms of local melting and probably also the plastic strain field, the melting behavior of the PEEK during the deposition was studied using the CTD analysis.

\section{Effect of $V_{\mathrm{p}}$ on the Deformation Features}

This section describes the effect of $V_{\mathrm{p}}$ on the features of the crater as well as the deformation behavior of the substrate. The variation of crater depth as a function of $V_{\mathrm{p}}$ ranging from 300 to $575 \mathrm{~m} / \mathrm{s}$ at long deposition times is shown in Fig. 5. At the velocity of $300 \mathrm{~m} / \mathrm{s}$, the crater depth is almost half the particle's diameter $\left(D_{p}=20 \mu \mathrm{m}\right)$ but exceeds beyond this value at velocities higher than $500 \mathrm{~m} / \mathrm{s}$. A linear increase in crater depth is detected within the 

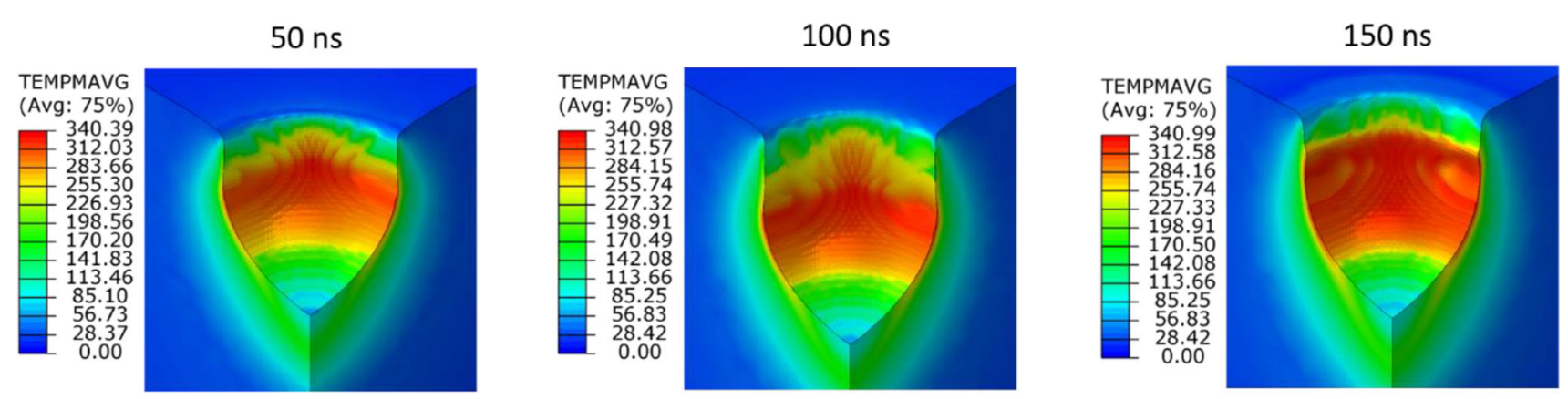

(a)
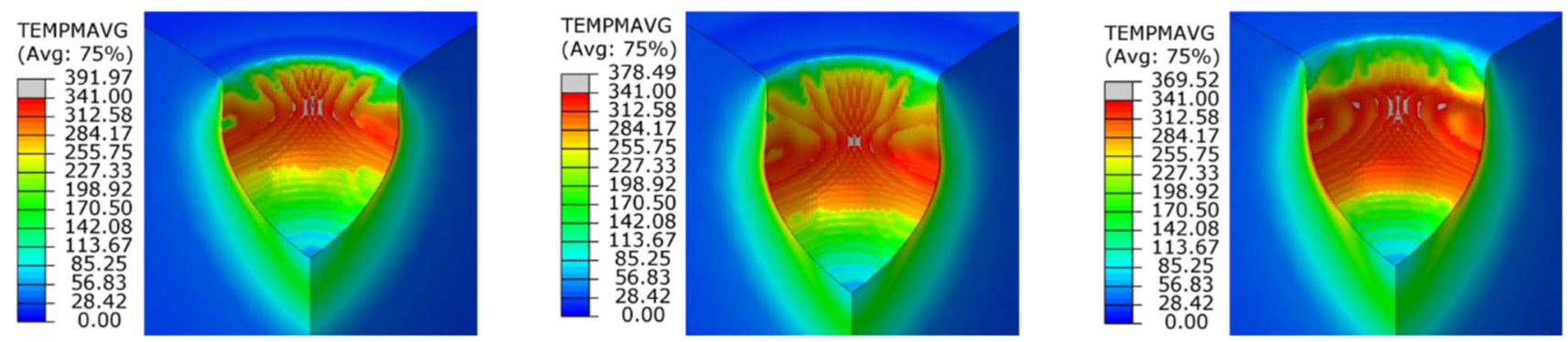

(b)

Fig. 4 Temperature distribution during the deposition of the particle with $T_{\mathrm{p}}=150{ }^{\circ} \mathrm{C}$ and $V_{\mathrm{p}}=400 \mathrm{~m} / \mathrm{s}$ using (a) adiabatic heat analysis and (b) coupled temperature-displacement analysis

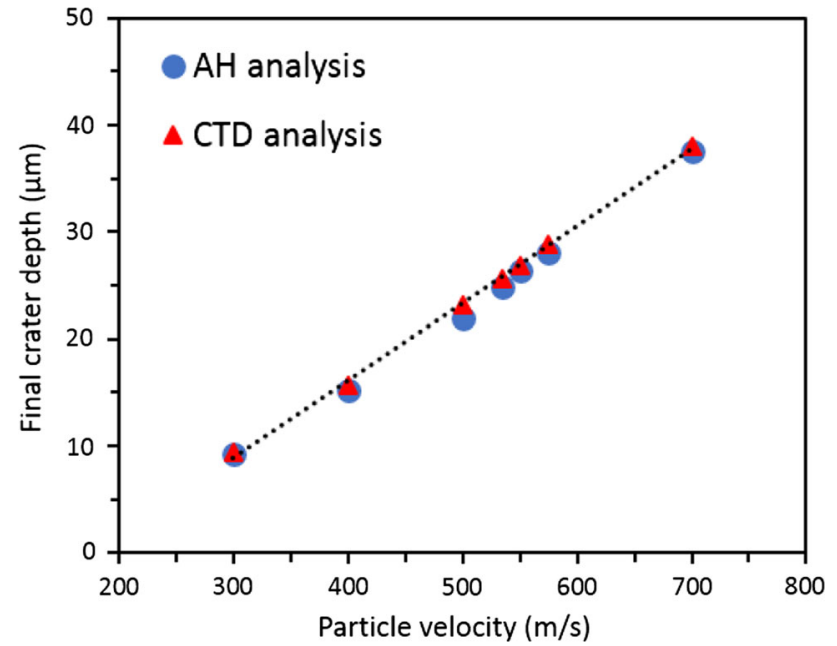

Fig. 5 Variation of the final crater depth as a function of particle velocity

investigated velocity range. As stated in the previous section, it is noticed that the analysis type (AH or CTD) has a negligible effect on the final crater depth, independently from the impact velocity.

Figure 6(a) shows the final stabilized situation of a single-particle deposition (either fully detached or anchored particle) at sufficiently long times. Here, the quarter model is mirrored to provide a clearer visualization of the deformation state. When the velocity is as low as $300 \mathrm{~m} / \mathrm{s}$, the particle kinetic energy is not sufficient to form a deep crater. As the velocity is increased, the penetration depth and the crater depth of the particle are increased, as well. At $400 \mathrm{~m} / \mathrm{s}$, an interaction zone is left around the perimeter of the crater at the surface. This interaction zone is formed during the particle rebound, causing a thin layer of the substrate very close to the particle/substrate contact region to be extruded upwards by particle displacement. This is due to the very soft and rubbery nature of the thermoplastic PEEK at temperatures higher than its glass transition temperature $\left(145{ }^{\circ} \mathrm{C}\right)$ (Ref 34$)$. At higher velocities, this phenomenon is more pronounced, and more substrate material is extruded since the particle travel distance during rebound has increased due to a greater penetration depth. At $500 \mathrm{~m} / \mathrm{s}$, the extruded material is torn off the substrate, but at $535 \mathrm{~m} / \mathrm{s}$, there is a weak link between the more continuous extruded material and the substrate. Most probably in practice, it will be washed away with the impact of the subsequent particles on the substrate. As the $V_{\mathrm{p}}$ increases further to $550 \mathrm{~m} / \mathrm{s}$ or $575 \mathrm{~m} / \mathrm{s}$, the extruded material grows in thickness and hinders the particle from exiting the crater. This condition shows a real embedment of the particle in the substrate, which could be considered as a mechanical interlock. It is noted that this lateral extrusion of the crater surface edges is a phenomenon different from conventional material jetting commonly observed in the CS of metallic substrates. Indeed, the PEEK material ejection occurs in the particle rebound phase and not during particle initial impact and penetration.

The proposed model is able to justify a number of observations reported in experimental trials for the 
(a)
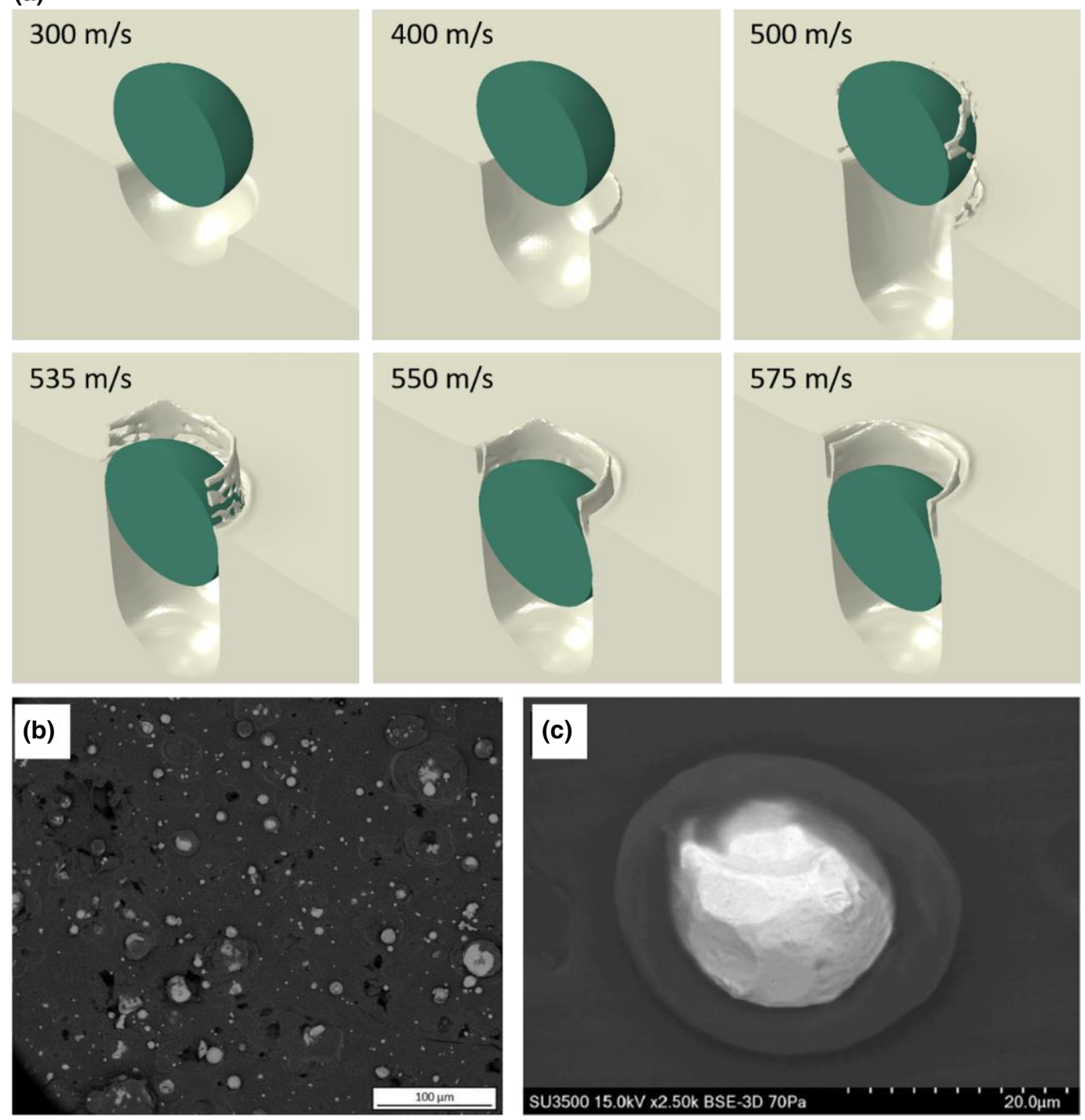

\section{(c)}

Fig. 6 (a) Final stabilized deformation contours of the substrate and a $20 \mu \mathrm{m}$ particle with $T_{\mathrm{p}}=150{ }^{\circ} \mathrm{C}$ and different particle velocities showing either full detachment or anchorage of the particle; backscattered electron micrographs of the sprayed PEEK surface after a

metallization of polymeric surfaces. The existence of empty craters after the deposition has been reported by research papers that performed the so-called "single-particle impact" deposition experiments of copper particles on PEEK (Ref 20, 35), performed either at high CS gun travel speeds or using a low powder feeding rate. Bortolussi (Ref 20) provided a relatively broad view of the surface after such a deposition test, as shown in Fig. 6(b). The average particle size matches well with the current study, and the average $V_{\mathrm{p}}$ is reported to be $560 \mathrm{~m} / \mathrm{s}$, with a relatively wide distribution of $V_{\mathrm{p}}$ from about 400 to $1000 \mathrm{~m} / \mathrm{s}$. Many single copper particle impact test derived from references (b) $T_{\mathrm{p}}=\sim 200{ }^{\circ} \mathrm{C}, V_{\mathrm{p}}=560 \mathrm{~m} / \mathrm{s}(\operatorname{Ref} 20)$ and (c) $T_{\mathrm{p}}=\sim 155^{\circ} \mathrm{C}$, $V_{\mathrm{p}}=530 \mathrm{~m} / \mathrm{s}(\operatorname{Ref} 35)$

empty craters are observed on the surface, displaying the situation that some fraction of the sprayed particles rebounded and detached from the substrate. It can be suggested that similar to the numerical effect perceived in Fig. 6(a), a single particle, even after a deep penetration into the substrate, is not able to remain anchored if its velocity is below a certain $V_{\mathrm{p}}$. However, at higher velocities, an embedment mechanism such as material extrusion is activated, which brakes the particle during the bounce. It is noted that due to the nature of the CS process, there exist statistically a relatively wide range of particle size and a 
corresponding range of $V_{\mathrm{p}}$, such that some particles could satisfy the embedment requirements and remain attached in the single-particle deposition test.

It could be seen in Fig. 6(a) that at sufficiently high velocities $(>550 \mathrm{~m} / \mathrm{s})$, the extruded substrate material appears as a thin layer. This layer might be folded down during the subsequent cooling or by the pressure exerted from the CS gas flow and even partially cover the particle at the perimeter. Similar features are observed in the experiments (Ref 20,35), as provided in Fig. 6(b) and (c). Particularly, the formation of an interaction zone is reported around the copper particle embedded into PEEK, as depicted in Fig. 6(c). Although the image is a backscattered electron micrograph and more reliable results could be inferred from secondary electron images, we envisage that the interaction zone could be formed by a similar extrusion phenomenon observed in the numerical simulations during the rebound phase. It is interesting to note the good agreement between the numerical and experimental results regarding the process parameters $\left(T_{\mathrm{p}}=\sim 200{ }^{\circ} \mathrm{C}, \quad V_{\mathrm{p}}=590 \mathrm{~m} / \mathrm{s} \quad(\operatorname{Ref} 20)\right.$ and $T_{\mathrm{p}}=$ $\sim 155^{\circ} \mathrm{C}, V_{\mathrm{p}}=530 \mathrm{~m} / \mathrm{s}$ (Ref 35)), which could be considered as a quantitative validation of the proposed model.

Analogous to the well-known critical velocity concept for the deposition of metals on metallic substrates (Ref 36), this numerical approach is able to identify the minimum interlocking velocity $\left(V_{\text {int }}\right)$ that has been proposed for metal impact on polymer, below which there is no effective mechanical interlocking of sprayed powders with the substrate (Ref 37). Specifically, regarding the case of copper particles on PEEK substrate, it does not seem probable to effectively embed a copper particle with $V_{\mathrm{p}}$ lower than $500-550 \mathrm{~m} / \mathrm{s}$ into the PEEK. However, it should be noted that continuous bombardment of the substrate by the lower $V_{\mathrm{p}}$ may bring about other situations than the single-particle deposition tests including the tamping effect of subsequent particles, the effect of substrate roughness and morphology. A similar condition is reflected in (Ref 37), with the remark that continuous CS of copper particles with an average size of $29 \mu \mathrm{m}$ at velocities as low as $225 \mathrm{~m} / \mathrm{s}$ did not produce a coating, i.e., deposition efficiency (DE) was close to zero, but individual particle anchorage could be achieved. "Drilled" craters as deep as three times the average particle size filled with particles observed on the cross-section might have been created by previously rebounded particles, which facilitated the trapping and interlocking of subsequent impacting particles. This condition will impart a serious damage to the polymer surface and will probably result in a more ragged interface between the substrate and the coating.

Within the gas stream of the CS, it can be argued that finer particles obtain a higher velocity since it would be more difficult to accelerate larger particles. Thus, fine powders are more successful in passing the minimum interlocking velocity. Gillet et al. (Ref 38 ) deposited fine $\left(d_{50}=10.3 \mu \mathrm{m}\right)$, medium $\left(d_{50}=23.2 \mu \mathrm{m}\right)$ and coarse $\left(d_{50}=37.9 \mu \mathrm{m}\right)$ copper powders using CS on a neat layer of PEEK fabricated on carbon fiber-reinforced polymer surface. Using the fine powder, it was possible to build up a thick coating with a DE $(\sim 28 \%)$ noticeably higher compared to other powder sizes, for which no successful deposition was achieved, and only isolated small aggregates were produced on the surface. The average in-flight particle velocity was reported to be around $400 \mathrm{~m} / \mathrm{s}$ with a range of $200-550 \mathrm{~m} / \mathrm{s}$ for the coarse and medium powders. Thus, the fine powder, with more particle fraction of high velocities, was successful in passing the $V_{\text {int }}$. requirement and developed the initial bond coating more successfully providing a stable basis for the build-up of the coating.

Although material extrusion during the bounce is suggested as an anchorage mechanism, it cannot be claimed as the only one because the formation of a relatively high density of empty craters as well as the gap below the anchored particle (Fig. 6a) discloses a new situation which demands considering other probable anchorage mechanisms. The gap was formed as a result of particle rebound and its stabilization at levels higher than the crater depth; i.e., the compressive forces applied by the adjacent polymer blocked the particle and did not allow it to drop down to the crater root. The formation of this gap has not been fully studied in the previous experimental investigations and requires future attention. However, we assume that the gap can be covered by the impact of the subsequent particles based on the experimental observations of continuous deposition or by the subsequent thermal contraction of the particle which may drive the particle down under its weight to fill the gap. Another reported anchorage mechanism is that wrinkles can be formed on the substrate around the deposited particle, especially when the substrate is preheated by being exposed to the processing gas (Ref 21), which was not included in the numerical simulations of the current study.

\section{Effect of $D_{\mathrm{p}}$ on $V_{\mathrm{int}}$}

It is interesting to investigate the effect of $D_{\mathrm{p}}$ variability on the deformations and $V_{\text {int }}$. Figure 7 shows the final state of impacted particles with $D_{\mathrm{p}}$ of 10,20 and $30 \mu \mathrm{m}$ after a long time $(1 \mu \mathrm{s})$ at the $V_{\mathrm{p}}$ of $535 \mathrm{~m} / \mathrm{s}$ and the $T_{\mathrm{p}}$ of $150{ }^{\circ} \mathrm{C}$. A full $360^{\circ}$ image is provided, and the fully torn sections of the substrate are removed to make the visual representation more clear. It is found that the particle anchorage is achieved at this velocity with different particle sizes. With the larger particle size of $30 \mu \mathrm{m}$, however, the anchorage seemed to be less, as a larger fraction of the particle 

showing the final state of the $\mathrm{Cu}$ particle with varying sizes of 10,20 and $30 \mu \mathrm{m}$ sprayed at a $V_{\mathrm{p}}=535 \mathrm{~m} / \mathrm{s}$ and $T_{\mathrm{p}}=150{ }^{\circ} \mathrm{C}$
Fig. 7 Deformation contours

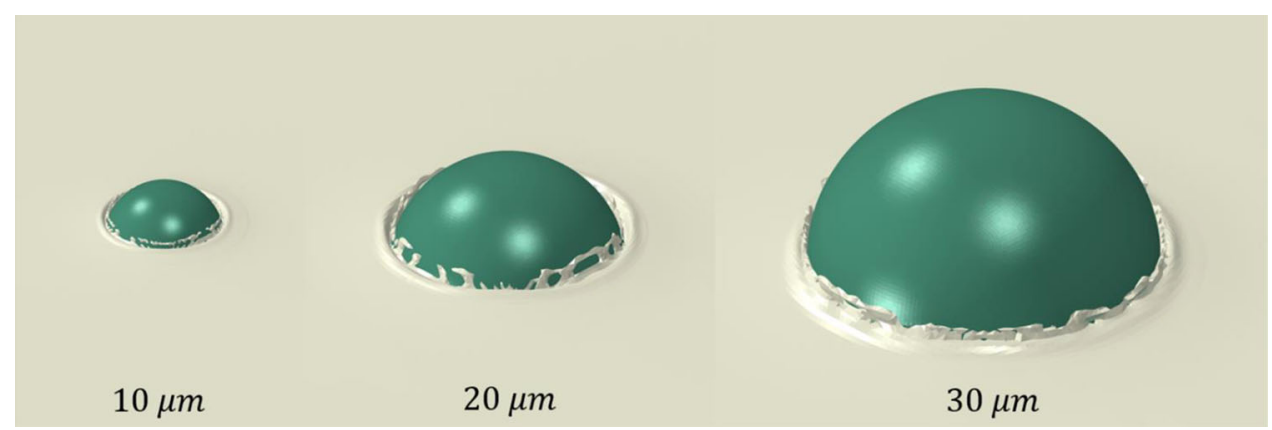

Fig. 8 Temperature contours of the substrate with $V_{\mathrm{p}}=$ $550 \mathrm{~m} / \mathrm{s}$ and $T_{\mathrm{p}}=150{ }^{\circ} \mathrm{C}$ at impact times of (a) $50 \mathrm{~ns}$ and (b) $170 \mathrm{~ns}$. The gray areas in the colored image depict melting

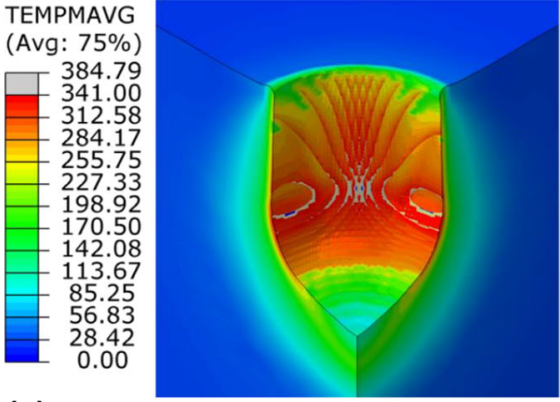

(a)

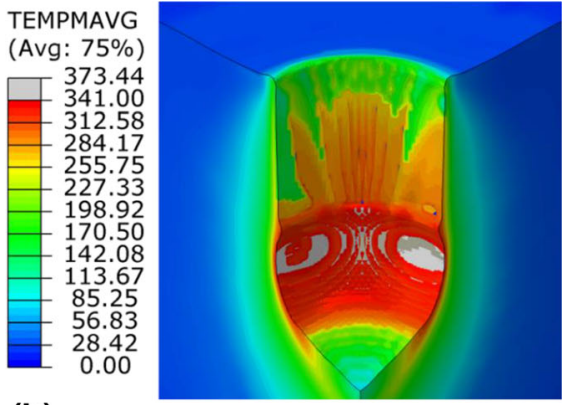

(b) remained outside of the PEEK and a small increase in the $V_{\mathrm{p}}$ could increase the amount of material extrusion and guarantee a stronger bond. The 10 and $30 \mu \mathrm{m}$ particles were detached from the substrate and did not remain anchored with a $V_{\mathrm{p}}=500 \mathrm{~m} / \mathrm{s}$, very similar to a $20 \mu \mathrm{m}$ particle (Fig. 5a), but the relevant contours were not included here for brevity. Thus, it can be suggested that the particle anchorage for different particle sizes in the studied range could be attained with a particle impact velocity of $\sim 535-550 \mathrm{~m} / \mathrm{s}$. Keeping the other variables constants, it is deduced that the particle size has a minor effect on the mechanical interlocking, as long as the impact velocity is high enough to guarantee particle partial penetration into the substrate. Although the kinetic energy increases with an increase in $D_{\mathrm{p}}$, the velocity plays a more pronounced role as the energy is proportional to the square power of the velocity.

\section{Substrate Melting}

The numerical investigations in this study confirm the occurrence of limited substrate superficial melting inside the crater (Fig. 8). The results indicate that with increasing, more substrate material will be prone to melting. Figure 8 shows the temperature field of the substrate in the intermediate stages of the particle impact at a $V_{\mathrm{p}}$ of $550 \mathrm{~m} / \mathrm{s}$ and $T_{\mathrm{p}}$ of $150{ }^{\circ} \mathrm{C}$. The gray areas in the colored contour show regions with a temperature above the melting point of the substrate. With an increase in $V_{\mathrm{p}}$, the size of the melted zone increases to some extent. This is mainly because the extent of the deformation increases with increasing velocity; thus, more plastic energy is dissipated through heat generation. The melted zone is very limited in depth and size with respect to the crater dimension. An increase in substrate temperature over room temperature would often occur during conventional CS at high exposure times, but it cannot be relevant for the single-particle impact tests where the gun travel speed is set fairly high.

Evidence of partial substrate melting is mentioned in the literature. For instance, Che et al. (Ref 35) discovered some traces of melted PEEK in the empty craters after particle rebound at an average $V_{\mathrm{p}}$ of $505 \mathrm{~m} / \mathrm{s}$ and $T_{\mathrm{p}}$ of $110{ }^{\circ} \mathrm{C}$. However, whether superficial melting of the substrate could or should be considered as an underlying or aiding mechanism in the particle embedment is still not clear. The melted polymer can act as a glue to grab and decelerate the particle and contribute to the mechanical interlocking.

\section{Conclusion}

This study was devised to numerically investigate the initial bond formation in the metallization of polymeric materials by cold spray. Single-particle impact simulations were conducted on a copper particle-PEEK substrate system using a coupled Eulerian-Lagrangian frame; various deformation indexes were compared and discussed against experimental observations from multiple reference studies, 
using the same material combination and range of spray parameters. The effects of particle velocity and size on the impact behavior and bond formation were examined. The following conclusions are drawn:

- The developed coupled Eulerian-Lagrangian model was successfully exploited in bypassing the numerical issues of element distortion in the soft polymeric substrate and hence provided a realistic deformation behavior of the polymer.

- The proposed model was found efficient in capturing the mechanical interlocking of the impacting particle and the substrate, and in predicting the required parametric conditions for the particle-to-substrate bonding. This numerical approach can be useful to practically select and optimize the experimental parameters of cold spray to deposit metallic powder on polymeric surfaces, as well as on composites with the polymeric matrix.

- The numerical simulations were able to demonstrate that the particle velocity must be higher than a critical value for an effective particle anchorage, as reported in experimental tests; the threshold value can be estimated using this model.

- The numerical model confirmed the occurrence of substrate melting during the particle impact at sufficiently large velocities, in line with previous experimental observations. The melted zone was superficial and relatively small with respect to the crater size, and the increase in the particle velocity caused growth of the melt extent.

\section{Supplementary Data}

Fig. S1 depicts the bilinear calibration of PEEK yield stress vs. strain rate and temperature.

\begin{abstract}
Acknowledgment This research is part of the project COSMEC (Cold Spray of Metal to Composite), funded by the Italian Ministry of University and Research (MUR) under the call "Progetti di Ricerca di Rilevante Interesse Nazionale - PRIN 2017”, grant 2017N4422T.
\end{abstract}

Funding Open access funding provided by Politecnico di Milano within the CRUI-CARE Agreement.

Open Access This article is licensed under a Creative Commons Attribution 4.0 International License, which permits use, sharing, adaptation, distribution and reproduction in any medium or format, as long as you give appropriate credit to the original author(s) and the source, provide a link to the Creative Commons licence, and indicate if changes were made. The images or other third party material in this article are included in the article's Creative Commons licence, unless indicated otherwise in a credit line to the material. If material is not included in the article's Creative Commons licence and your intended use is not permitted by statutory regulation or exceeds the permitted use, you will need to obtain permission directly from the copyright holder. To view a copy of this licence, visit http://creativecommons. org/licenses/by/4.0/.

\section{References}

1. R.N. Raoelison, Y. Xie, T. Sapanathan, M.P. Planche, R. Kromer, S. Costil and C. Langlade, Cold Gas Dynamic Spray Technology: a Comprehensive Review of Processing Conditions for Various Technological Developments Till to Date, Addit. Manuf., 2018, 19, p 134-159. https://doi.org/10.1016/j.addma.2017.07.001

2. H. Assadi, F. Gärtner, T. Stoltenhoff and H. Kreye, Bonding Mechanism in Cold Gas Spraying, Acta Mater., 2003, 51, p 4379-4394. https://doi.org/10.1016/S1359-6454(03)00274-X

3. S. Bagherifard and M. Guagliano, Fatigue Performance of Cold Spray Deposits: Coating, Repair and Additive Manufacturing Cases, Int. J. Fatigue, 2020, 139, p 105744. https://doi.org/10. 1016/j.ijfatigue.2020.105744

4. S. Bagherifard, A. Heydari Astaraee, M. Locati, A. Nawaz, S. Monti, J. Kondás, R. Singh, M. Guagliano, Design and analysis of Additive Manufactured Bimodal Structures Obtained by Cold Spray Deposition, Addit. Manuf., 2020, 33, 101131. https://doi. org/10.1016/j.addma.2020.101131

5. P. Lomonaco, S. Weiller, I. Feki, A. Debray, F. Delloro, M. Jeandin, B. Favini and C. Rossignol, Cold Spray Technology to Promote Conductivity of Short Carbon Fiber Reinforced Polyether-Ether-Ketone (PEEK), Key Eng. Mater., 2019, 813, p 459-464.

6. A.S. Perna, A. Viscusi, A. Astarita, L. Boccarusso, L. Carrino, M. Durante and R. Sansone, Manufacturing of a Metal Matrix Composite Coating on a Polymer Matrix Composite Through Cold Gas Dynamic Spray Technique, J. Mater. Eng. Perform., 2019, 28, p 3211-3219. https://doi.org/10.1007/s11665-01903914-6

7. S. Geetha, K.K. S. Kumar, C.R.K. Rao, M. Vijayan, D.C. Trivedi, EMI Shielding: Methods and Materials-a Review, J. Appl. Polym. Sci., 2009, 112, 2073-2086. https://doi.org/10.1002/app. 29812

8. H. Che, M. Gagné, P.S.M. Rajesh, J.E. Klemberg-Sapieha, F. Sirois, D. Therriault and S. Yue, Metallization of Carbon Fiber Reinforced Polymers for Lightning Strike Protection, J. Mater. Eng. Perform., 2018, 27, p 5205-5211. https://doi.org/10.1007/ s11665-018-3609-y

9. K.M.M. Żenkiewicz, P. Rytlewski, M. Stepczyńska and B. Jagodziński, Electroless Metallization of Polymers, Arch. Mater. Sci. Eng., 2015, 74, p 67-76.

10. J. Siegel, V. Kotál, Preparation of Thin Metal Layers on Polymers, Acta Polytech., 2007, 47. https://doi.org/10.14311/904

11. T. Duguet, F. Senocq, L. Laffont and C. Vahlas, Metallization of Polymer Composites by Metalorganic Chemical Vapor Deposition of $\mathrm{Cu}$ : Surface Functionalization Driven Films Characteristics, Surf. Coat. Technol., 2013, 230, p 254-259. https://doi.org/ 10.1016/j.surfcoat.2013.06.065

12. R. Gonzalez, H. Ashrafizadeh, A. Lopera, P. Mertiny and A. McDonald, A Review of Thermal Spray Metallization of Polymer-Based Structures, J. Therm. Spray Technol., 2016, 25, p 897-919. https://doi.org/10.1007/s11666-016-0415-7

13. A. Sturgeon, B. Dunn, S. Celotto, O'Neill, Cold Sprayed Coatings for Polymercomposite Substrate. In: 10th International Symposium on Materials in a Space Environment, Collioure, France, 2006

14. A. Astarita, L. Boccarusso, L. Carrino, M. Durante, A.S. Perna, A. Viscusi, Cold Spray Deposition on Polymeric and Composite 
Substrates. Cold Spray in the Realm of Additive Manufacturing, Springer, 2020, pp 87-128.

15. H. Assadi, F. Gärtner, T. Klassen and H. Kreye, Comment on 'Adiabatic Shear Instability is not Necessary for Adhesion in Cold Spray,' Scripta Mater., 2019, 162, p 512-514. https://doi. org/10.1016/j.scriptamat.2018.10.036

16. H. Che, P. Vo and S. Yue, Metallization of Carbon Fibre Reinforced Polymers by Cold Spray, Surf. Coat. Technol., 2017, 313, p 236-247. https://doi.org/10.1016/j.surfcoat.2017.01.083

17. H. Assadi, F. Gärtner, T.J. Klassen, Modeling and Simulation of Cold Spray. In: C.M. Kay, J. Karthikeyan (Eds.), High Pressure Cold Spray: Principles and Applications, ASM International, United States of America, 2019

18. S. Weiller, F. Delloro, P. Lomonaco, M. Jeandin, C. Garion, A Finite Elements Study on Porosity Creation Mechanisms in Cold Sprayed Coatings. Key Eng. Mater., 2019, pp 358-363. https:// doi.org/10.4028/www.scientific.net/KEM.813.358

19. A. Małachowska, Analysis of the Cold Gas Spraying Process and Determination of Selected Properties of Metallic Coatings on Polymers, Ph.D. Thesis, Wroclaw University of Technology (Poland) and University of Limoges (France), 2016

20. V. Bortolussi, Experimental and Numerical Study of the Electrical Conductivity of Cold Spray Metal-Polymer Composite Coatings on Carbon Fiber-Reinforced Polymer, Ph.D. Thesis, Université Paris sciences et lettres, 2016

21. C. Chen, X. Xie, Y. Xie, X. Yan, C. Huang, S. Deng, Z. Ren and H. Liao, Metallization of Polyether Ether Ketone (PEEK) by Copper Coating via Cold Spray, Surf. Coat. Technol., 2018, 342, p 209-219. https://doi.org/10.1016/j.surfcoat.2018.02.087

22. D. Giraud, F. Borit, V. Guipont, M. Jeandin, J. Malhaire, Metallization of a Polymer Using Cold Spray: Application to Aluminum Coating of Polyamide 66. In: International Thermal Spray Conference and Exposition-Air, Land, Water and the Human Body: Thermal Spray Science and Applications, ITSC 2012, Houston, TX; United States, 2012, pp 21-24.

23. W.Y. Li, K. Yang, S. Yin and X.P. Guo, Numerical Analysis of Cold Spray Particles Impacting Behavior by the Eulerian Method: A Review, J. Therm. Spray Technol., 2016, 25, p 1441-1460. https://doi.org/10.1007/s11666-016-0443-3

24. D. Systèmes, Simulia User Assistance, 2019

25. H. Unal and A. Mimaroglu, Friction and Wear Characteristics of PEEK and its Composite under Water Lubrication, J. Reinf. Plast. Compos., 2006, 25, p 1659-1667. https://doi.org/10.1177/ 0731684406068406

26. L. Zsidai and Z. Szakál, Friction of PA6 and Peek Composites in the Light of their Surface Characteristics, Mech. Eng. Lett. R D, 2014, 11, p 151-163.

27. G. Johnson, W.H. Cook, A Constitutive Model and Data for Metals Subjected to Large Strains, High Strain Rates and High Temperatures. In: The 7th International Symposium on Ballistics, 1983, pp 541-547.
28. Q. Wang, X. Luo, S. Tsutsumi, T. Sasaki, C. Li, N. Ma, Measurement and Analysis of Cold Spray Residual Stress Using Arbitrary Lagrangian-Eulerian Method, Addit. Manuf., 2020, 35. https://doi.org/10.1016/j.addma.2020.101296

29. D. Garcia-Gonzalez, A. Rusinek, T. Jankowiak and A. Arias, Mechanical Impact Behavior of Polyether-Ether-Ketone (PEEK), Compos. Struct., 2015, 124, p 88-99. https://doi.org/10. 1016/j.compstruct.2014.12.061

30. P.J. Rae, E.N. Brown and E.B. Orler, The Mechanical Properties of Poly(Ether-Ether-Ketone) (PEEK) with Emphasis on the Large Compressive Strain Response, Polymer, 2007, 48, p 598-615. https://doi.org/10.1016/j.polymer.2006.11.032

31. Z. El-Qoubaa and R. Othman, Temperature, Strain Rate and Pressure Sensitivity of the Polyetheretherketone's Yield Stress, Int. J. Appl. Mech., 2017, 09, p 1750099. https://doi.org/10.1142/ S1758825117500995

32. M. Koerdt, M. Koerdt, T. Grobrüg, M. Skowronek, A.S. Herrmann, Modelling and Analysis of the Thermal Characteristic of Thermoplastic Composites from Hybrid Textiles During Compression Moulding, J. Thermoplast. Compos. Mater., 2016, 0892705719875204. https://doi.org/10.1177/0892705719875204

33. D. Barba, A. Arias and D. Garcia-Gonzalez, Temperature and Strain Rate Dependences on Hardening and Softening Behaviours in Semi-Crystalline Polymers: Application to PEEK, Int. J. Solids Struct., 2020, 182-183, p 205-217. https://doi.org/10.1016/j. ijsolstr.2019.08.021

34. A.A. Goodwin and G.P. Simon, Glass Transition Behaviour of Poly(Ether Ether Ketone)/Poly(Ether Imide) Blends, Polymer, 1996, 37, p 991-995. https://doi.org/10.1016/00323861(96)87282-X

35. H. Che, P. Vo and S. Yue, Investigation of Cold Spray on Polymers by Single Particle Impact Experiments, J. Therm. Spray Technol., 2019, 28, p 135-143. https://doi.org/10.1007/s11666018-0801-4

36. D.L. Gilmore, R.C. Dykhuizen, R.A. Neiser, M.F. Smith and T.J. Roemer, Particle Velocity and Deposition Efficiency in the Cold Spray Process, J. Therm. Spray Technol., 1999, 8, p 576-582. https://doi.org/10.1361/105996399770350278

37. H. Che, X. Chu, P. Vo and S. Yue, Metallization of Various Polymers by Cold Spray, J. Therm. Spray Technol., 2018, 27, p 169-178. https://doi.org/10.1007/s11666-017-0663-1

38. V. Gillet, E. Aubignat, S. Costil, B. Courant, C. Langlade, P. Casari, W. Knapp and M.P. Planche, Development of Low Pressure Cold Sprayed Copper Coatings on Carbon Fiber Reinforced Polymer (CFRP), Surf. Coat. Technol., 2019, 364, p 306-316. https://doi.org/10.1016/j.surfcoat.2019.01.011

Publisher's Note Springer Nature remains neutral with regard to jurisdictional claims in published maps and institutional affiliations. 